\title{
Efektivitas Komposit Material Overburden Batubara, Zeolit, dan Arang Aktif Tempurung Kelapa Sebagai Adsorben Besi dalam Air Asam Tambang
}

\author{
Mycelia Paradise ${ }^{1,2}{ }^{*}$, Edy Nursanto ${ }^{1}$, Nurkhamim ${ }^{1}$ \\ 'Program Magister Teknik Pertambangan, Universitas Pembangunan Nasional "Veteran" Yogyakarta, \\ Yogyakarta 55283, Indonesia \\ 2 Jurusan Teknik Pertambangan, Institut Teknologi Nasional Yogyakarta, Yogyakarta 55281, Indonesia \\ *Correspondence: mycelia@itny.ac.id
}

Received: 16 April 2021; Accepted: 22 May 2021; Published: 20 June 2021

\begin{abstract}
Abstrak: Penelitian ini mempelajari penyerapan Fe dari air asam tambang yang berasal dari lokasi penambangan batubara. Adsorben yang digunakan dalam penelitian ini yaitu kombinasi antara claystone, zeolit, dan arang aktif tempurung kelapa. Adsorben tersebut harus diaktivasi terlebih dahulu untuk membersihkan pengotor di permukaannya sehingga luas permukaannya meningkat. Aktivasi claystone dilakukan dengan $3 \mathrm{M} \mathrm{NaOH}$, zeolit dengan $3 \mathrm{M} \mathrm{HCl}$, dan arang tempurung kelapa dengan $4 \mathrm{M} \mathrm{HCl}$. Komposit dibuat dengan mencampurkan ketiga adsorben dengan perbandingan (Claystone[C]: Zeolit[Z]: Arang aktif[A]) $=25: 25: 50$. Hasil uji luas permukaan menunjukkan bahwa komposit memiliki luas permukaan $62,44 \mathrm{~m}^{2} / \mathrm{g}$. Adsorpsi dilakukan dengan sistem batch menggunakan alat hot plate stirer pada variasi waktu kontak 30, 60, 90, 120, dan 150 menit. Berdasarkan hasil uji adsorpsi, 7,5 gram komposit mampu menurunkan konsentrasi Fe dengan efektivitas $99,61 \%$ dan kapasitas adsorpsi 0,432 mg/g pada waktu kontak 30 menit.
\end{abstract}

Kata Kunci: adsorpsi, komposit, efektivitas, kapasitas

\begin{abstract}
This research studied adsorption iron (Fe) from acid mine drainage in coal mining. Adsorbent used in this research is the combination of activated claystone, activated zeolite, and ativated carbon from coconut shell. The adsorbents need to be activated to remove the impurities from its surface and improved

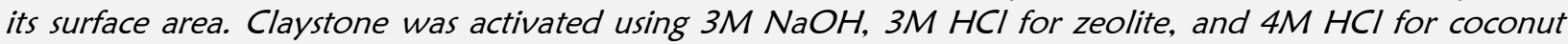
shell. Composite was made by mixing claystone, zeolite, and coconut shell with 3 ratio (claystone [C], zeolite [Z], activated carbon [A]) $=25: 25: 50$. The result of surface area analyzer showed that the surface area of composite was $62,44 \mathrm{m2} / \mathrm{g}$. Adsorption with batch system was carried out using hot plate stirer on 30,60, 90, 120, and 150 minutes of contact time. Adsorption result showed that 7,5 gram of composite succeded decreasing iron metal concentration with $99,61 \%$ effectiveness and $0,432 \mathrm{mg} / \mathrm{g}$ adsorption capacity on 30 minutes of contact time.
\end{abstract}

Keywords: adsorption, composite, efectiveness, capacity

\section{PENDAHULUAN}

Penambangan batubara memegang peranan penting bagi perekonomian negara. Salah satu tahapan dalam penambangan yaitu pembongkaran batuan penutup (overburden). Volume batuan penutup yang sangat banyak hingga kini belum dimanfaatkan secara optimal sehingga bisa disebut sebagai limbah. Material overburden berpotensi menyebabkan terjadinya air asam apabila beraksi dengan oksigen dan air. Air Asam Tambang (AAT) yaitu air 
dengan Nilai $\mathrm{pH}$ rendah dan tingkat kelarutan logam yang tinggi (Indra, 2014 dalam Gobel, 2018). Air asam mengandung banyak logam berat, salah satunya adalah besi (Fe). Berdasarkan Keputusan Menteri Lingkungan Hidup Nomor 113 Tahun 2003 tentang Baku Mutu Air Limbah Bagi Usaha dan atau Kegiatan Pertambangan Batubara, kadar maksimum besi total adalah $7 \mathrm{mg} / \mathrm{l}$. Ada banyak metode untuk menurunkan logam berat dari air asam tambang, diantaranya osmosis balik, presipitasi bahan kimia, pertukaran ion, dan adsorpsi.

Diantara beberapa metode tersebut, adsorpsi dipandang sebagai metode yang efektif karena rendahnya biaya yang dibutuhkan dan ketersediaan adsorben di alam yang melimpah. Penelitian tentang adsorpsi dengan zeolit dan arang aktif tempurung kelapa telah banyak dilakukan, namun penelitian tentang penggabungan claystone, zeolit, dan arang aktif tempurung kelapa belum pernah dilakukan sebelumnya. Penelitian ini memanfaatkan limbah batuan penutup dalam penambangan batubara yaitu claystone untuk dicampur dengan zeolit dan arang aktif tempurung kelapa. Campuran tersebut disebut komposit. Komposit akan digunakan sebagai adsorben untuk menyerap Fe dalam AAT melalui proses adsorpsi. Daya jerap yang kuat pada Claystone dapat digunakan untuk menurunkan konsentrasi logam berat (Musso et al., 2014). Rongga pada zeolit dapat menyemat logam berat (Catri, 2016). Pori dalam arang tempurung kelapa menyebabkan arang tempurung kelapa memiliki luas permukaan yang besar sehingga dapat menyerap logam berat (Li et al., 2009). Tujuan penelitian ini adalah untuk menganalisis kemampuan penyerapan Fe oleh campuran yang terdiri dari claystone, zeolit, dan arang tempurung kelapa. Penelitian ini diharapkan akan memberikan manfaat penyediaan material sebagai penyerap logam berat dalam AAT menggunakan adsorben berbiaya rendah. Selain itu penelitian ini diharapkan akan meningkatkan nilai keekonomian claystone, zeolit, dan arang tempurung kelapa.

\section{METODE PENELITIAN}

Alat

Hot plate stirer, gelas beker, neraca analitik, erlenmeyer, spatula, cawan petri, corong kaca, gelas ukur, oven, tungku, tangkrus.

\section{Bahan}

Claystone dari material overburden pada pertambangan batubara, zeolit dari Klaten, tempurung kelapa dari Bontang, $\mathrm{HCl}$ p.a (merck), $\mathrm{NaOH}$ p.a (Merck), akuades.

\section{Preparasi Adsorben}

- Claystone ditumbuk, dan diayak dengan ayakan 100 mesh, dicuci dengan akuades, disaring, dan dikeringkan pada suhu $105^{\circ} \mathrm{C}$ selama 4 jam. Diaktivasi kimia dengan merendam 150 gram claystone pada gelas beker berisi $300 \mathrm{ml} \mathrm{NaOH} 3 \mathrm{M}$. Larutan disaring dengan kertas saring whatman No. 41, residu dicuci dengan akuades, dan dipanaskan pada tungku dengan suhu $700^{\circ} \mathrm{C}$ selama 30 menit dan didinginkan sampai suhu ruang (Nwosu et al., 2018; Mukarrom et al., 2020).

- Zeolit ditumbuk dan diayak dengan ayakan 100 mesh. Zeolit direndam dalam akuades selama 24 jam, disaring, dan dikeringkan pada suhu $120^{\circ} \mathrm{C}$ selama 24 jam. Diaktivasi kimia dengan merendam 150 gram zeolit kedalam gelas beker berisi $300 \mathrm{ml} \mathrm{HCl} 3 \mathrm{M}$. Larutan disaring dengan kertas saring, residu dicuci dengan akuades, dikeringkan pada temperatur $80^{\circ} \mathrm{C}$ selama 24 jam, dan didinginkan sampai suhu ruang.

- Arang tempurung kelapa ditumbuk dan diayak dengan ayakan 100 mesh. Arang tempurung kelapa diaktivasi dengan cara merendam 150 gram arang tempurung kelapa pada gelas beker berisi $300 \mathrm{ml} \mathrm{HCl} \mathrm{4M}$. Larutan disaring dengan kertas saring, residu dicuci dengan akuades, dipanaskan pada suhu $110^{\circ} \mathrm{C}$ selama 3 jam, dan didinginkan sampai suhu ruang (Tan et al., 2017; Martini et al., 2020). 


\section{Pembuatan Komposit}

Komposit dibuat dengan mencampurkan claystone teraktivasi, zeolit teraktivasi, dan arang aktif tempurung kelapa dengan 3 perbandingan yaitu: (claystone [C] : zeolit [Z] : arang aktif $[\mathrm{A}])=50: 25: 25 ; 25: 25: 50 ;$ dan 25:50:25. Komposit dikarakterisasi menggunakan $X$-Ray Diffraction untuk menentukan kandungan mineral dalam adsorben dan Surface Area Analyzer untuk menentukan luas permukaannya.

\section{Adsorpsi Fe dari AAT}

Adsorpsi dilakukan menggunakan alat hot plate stirer. Volume air asam tambang yang digunakan adalah $250 \mathrm{ml}$, kecepatan pengadukan $300 \mathrm{rpm}$, berat komposit 7,5 gram, dengan variasi waktu kontak 30, 60, 90, 120, dan 150 menit. Kapasitas adsorpsi (mg/g) dan efektivitas adsorpsi (\%) dihitung menggunakan rumus (1) dan (2) (Balintova et al., 2014):

$$
\begin{aligned}
\frac{x}{m} & =\frac{(C o-C e) \cdot V}{W} \\
Q & =\frac{(C o-C e)}{C o} \times 100 \%
\end{aligned}
$$

$\frac{x}{m}$ adalah kapasitas adsorpsi, $Q$ adalah efektivitas adsorpsi, Co adalah konsentrasi awal dalam $\mathrm{mg} / \mathrm{l}, \quad C e$ adalah konsentrasi kesetimbangan pada waktu tertentu dalam $\mathrm{mg} / \mathrm{l}, \quad V$ adalah volume larutan dalam liter, dan $W$ adalah massa komposit dalam gram.

\section{HASIL DAN PEMBAHASAN}

\section{Karakterisasi Komposit dengan $X$-Ray Diffraction}

Karakterisasi komposit dengan $X$-Ray Diffraction bertujuan untuk mengetahui jenis mineral yang ada pada adsorben, sehingga diketahui kualitas material yang digunakan. Hasil uji X-Ray Diffraction dapat dilihat pada Gambar 1, Gambar 2, dan Gambar 3.

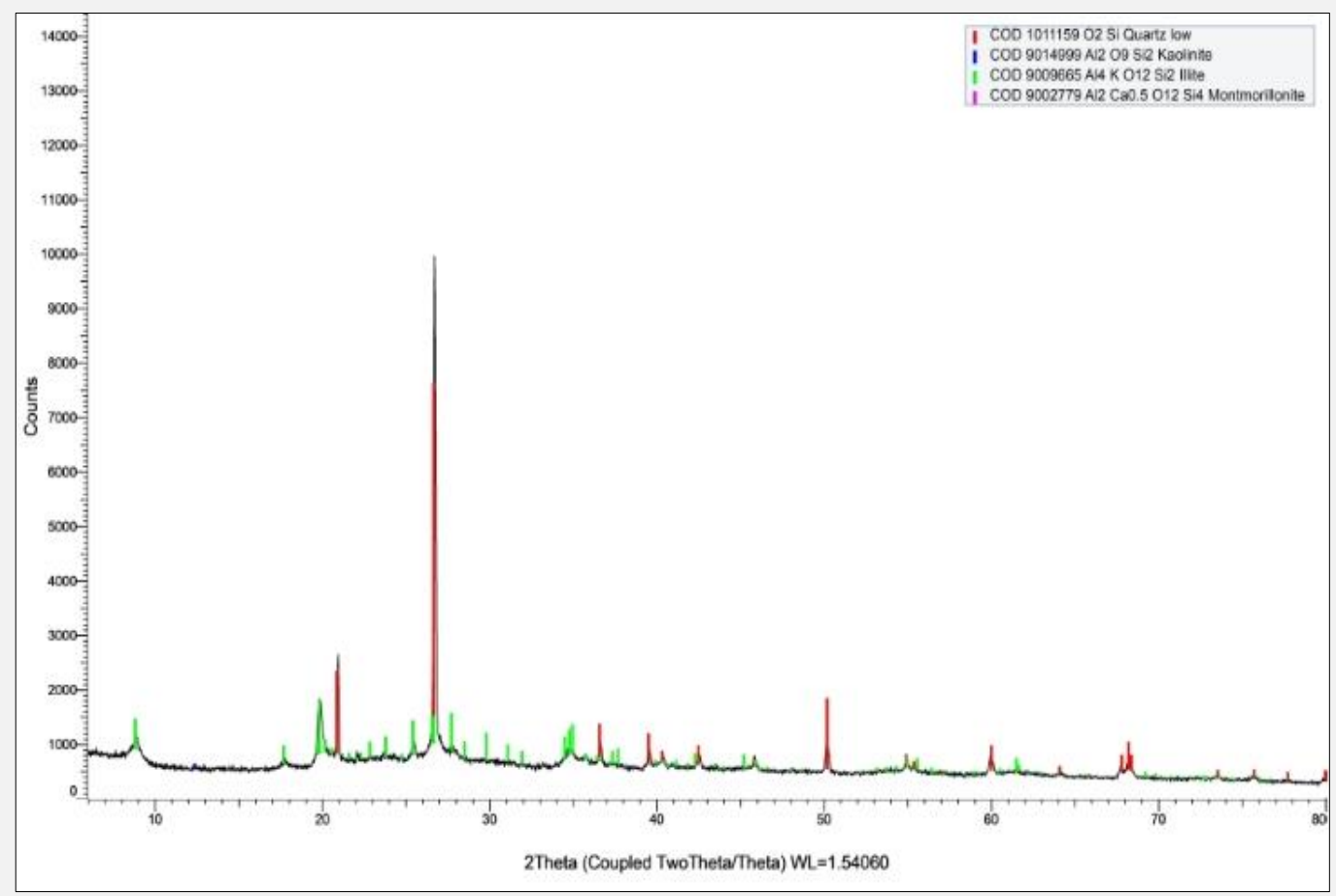

Gambar 1. Pola difraksi claystone teraktivasi 
Berdasarkan hasil uji X-Ray Diffraction pada Gambar 1, claystone yang digunakan dalam penelitian ini mengandung mineral kaolinit yang dominan dan sedikit montmorilonit. Kaolinit merupakan penyerap logam berat yang baik karena mengandung butiran yang sangat halus dan tersusun dari material lempung berkualitas tinggi dan memiliki luas permukaan yang besar hingga 13-21 m²/gram (Mgbemena et al., 2013).

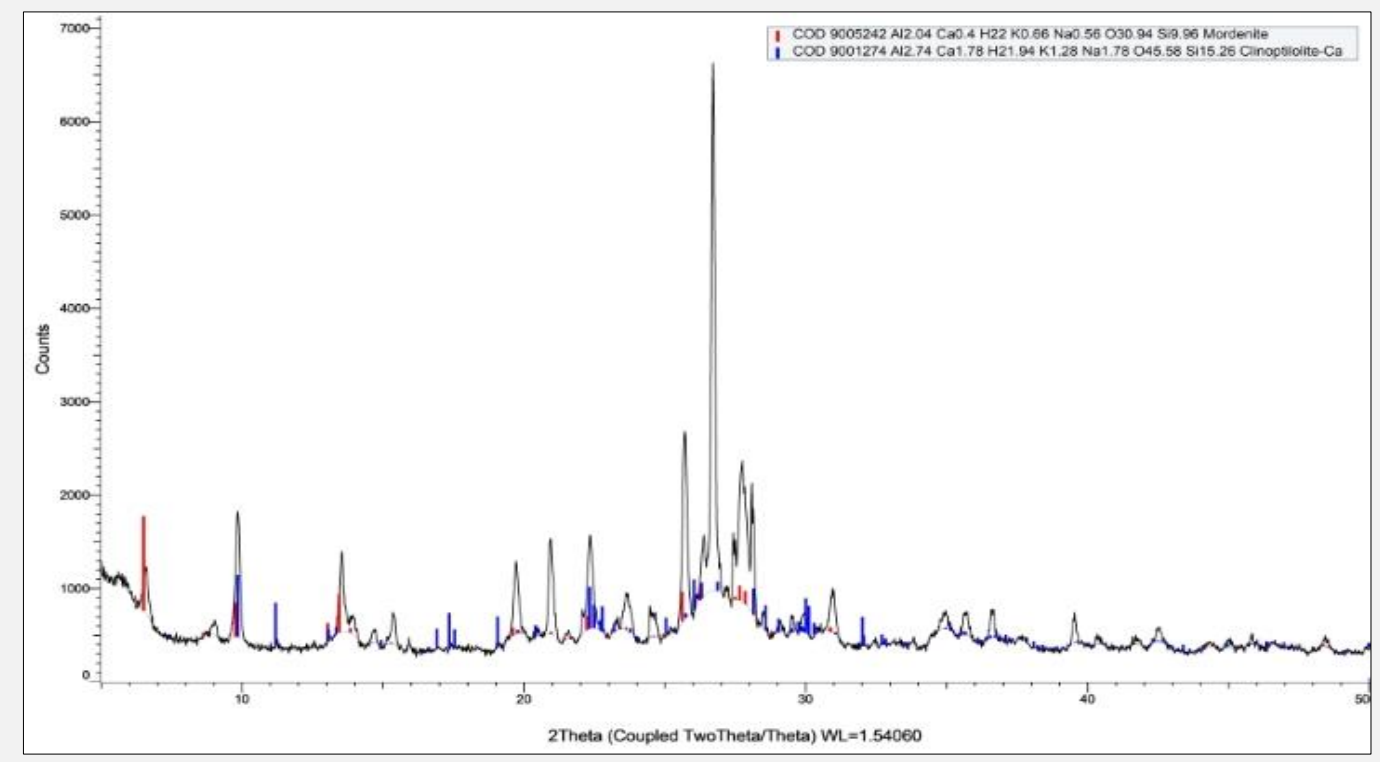

Gambar 2. Pola difraksi zeolit teraktivasi

Berdasarkan Gambar 2, Zeolit dalam penelitian ini mengandung mineral klipnotilolit dan mordenit yang dominan. Zeolit jenis ini memiliki beberapa kelebihan yaitu memiliki stabilitas termal yang tinggi hingga $800-900^{\circ} \mathrm{C}$, stabilitas tinggi terhadap perlakuan asam, dan rasio $\mathrm{Si}$ dan $\mathrm{Al}$ yang tinggi sehingga merupakan penyerap logam berat yang baik.

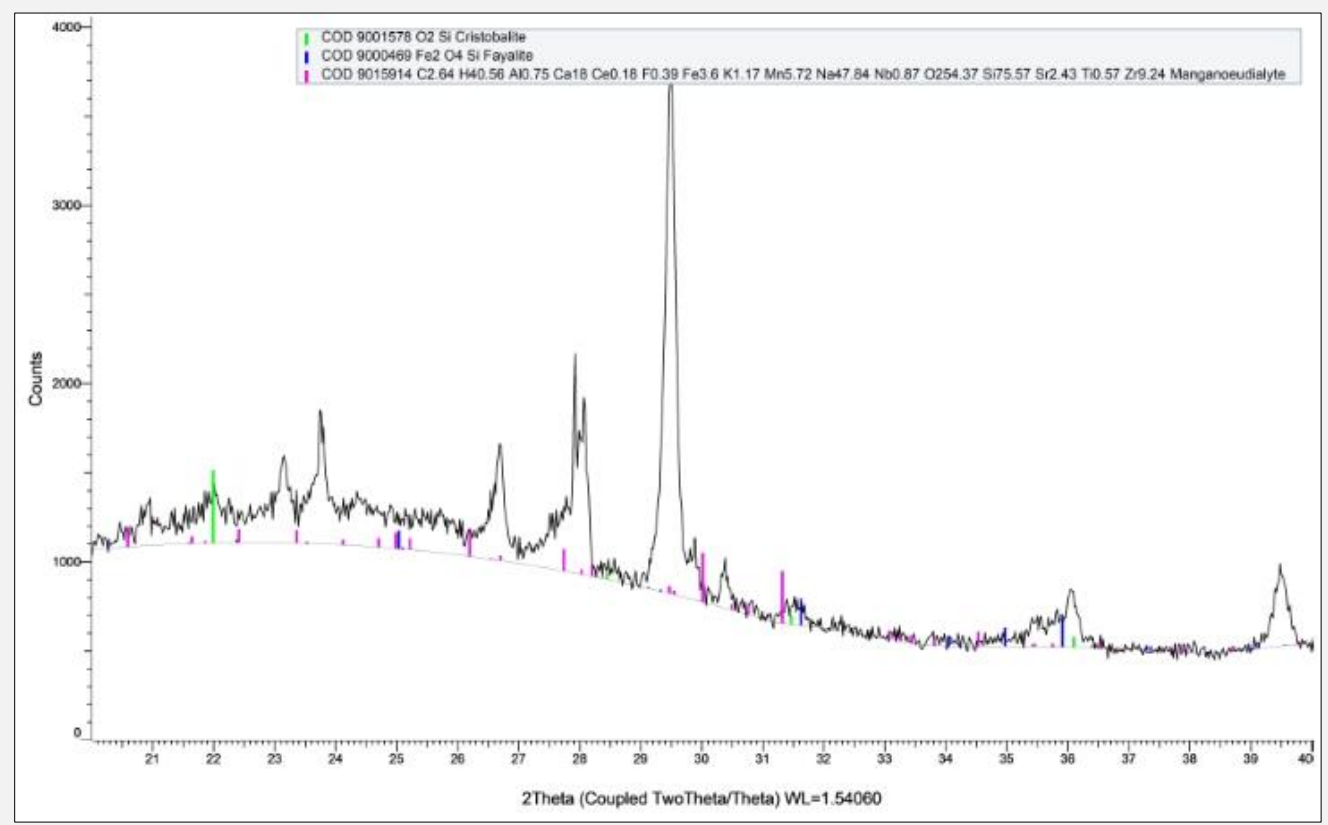

Gambar 3. Pola difraksi arang aktif tempurung kelapa 
Berdasarkan pola difraksi arang aktif pada Gambar 3, tempurung kelapa yang digunakan dalam penelitian ini mengandung mineral cristobalite, fayalite, dan manganodialite. Mineral tersebut menyebabkan arang tempurung kelapa memiliki kualitas pori yang banyak sebagai penyerap logam berat.

\section{Karakterisasi Komposit dengan Surface Area Analyzer}

Uji karakterisasi komposit menggunakan Surface Area Analyzer bertujuan untuk mengetahui luas permukaan komposit sebagai adsorben. Uji luas permukaan dilakukan terhadap 3 perbandingan komposit (claystone [C] : zeolit [Z] : arang aktif $[A]$ ) $=50: 25: 25$; 25:25:50 ; dan 25:50:25. Hasil uji luas permukaan menunjukkan bahwa komposit dengan perbandingan 25:25:50 merupakan komposit terbaik karena memiliki ukuran pori 3,7581 nm, volume pori $0,022073 \mathrm{~cm}^{3} / \mathrm{g}$, dan total luas permukaan terbesar yaitu $62,4423 \mathrm{~m}^{2} / \mathrm{g}$. Sementara dua komposit lainnya, yaitu komposit dengan perbandingan 50:25:25 memiliki luas permukaan $37,9774 \mathrm{~m}^{2} / \mathrm{g}$ dan komposit dengan perbandingan 25:50:25 memiliki luas permukaan $32,3444 \mathrm{~m}^{2} / \mathrm{g}$. Berdasarkan hasil uji luas permukaan, komposit dengan perbandingan 25:25:50 memiliki luas permukaan yang besar. Ukuran pori yang kecil menyebabkan luas permukaan semakin besar. Volume pori komposit juga banyak, sehingga komposit merupakan adsorben yang potensial untuk menyerap logam berat terlarut dalam air.

\section{Adsorpsi Fe}

Berdasarkan hasil uji adsorpsi dan analisa AAS, maka konsentrasi Fe dalam AAT pada berbagai variasi waktu kontak dapat dilihat pada Gambar 4 berikut.

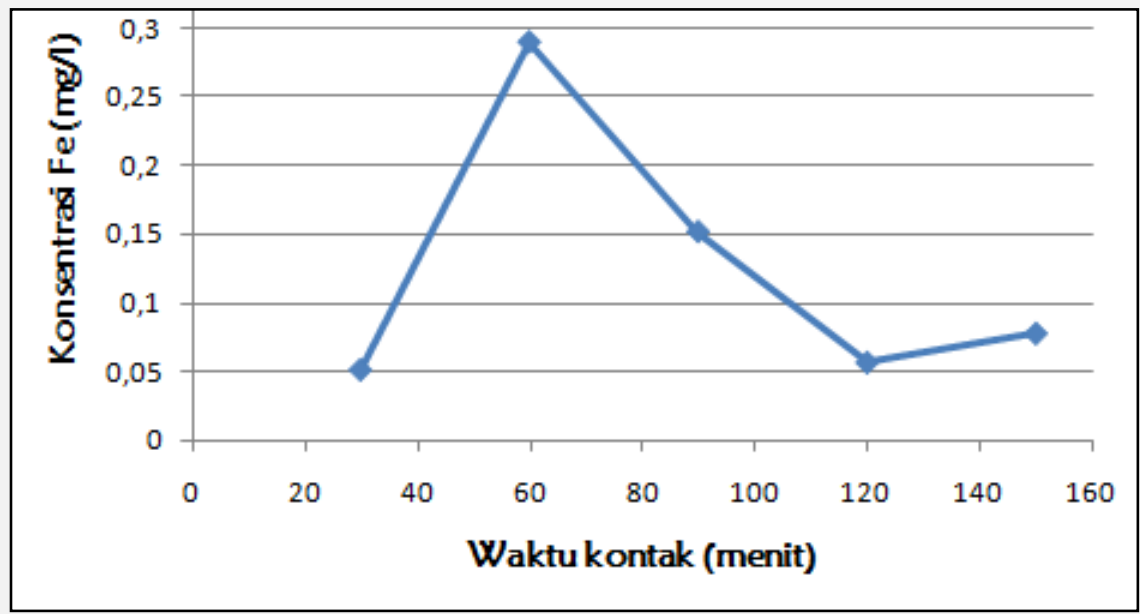

Gambar 4. Konsentrasi Fe setelah adsorpsi

Berdasarkan Gambar 4, komposit berhasil menurunkan konsentrasi Fe dari konsentrasi awal 13,006 mg/l menjadi $0,051 \mathrm{mg} / \mathrm{l}$ pada waktu kontak 30 menit. Konsentrasi $\mathrm{Fe}$ mengalami kenaikan pada menit ke 60 menjadi $0,2902 \mathrm{mg} / \mathrm{l}$, menandakan bahwa komposit telah jenuh sehingga melepaskan kembali sebagian Fe yang telah diserapnya. Konsentrasi Fe menurun kembali menjadi 0,152 pada waktu kontak 90 menit, 0,0563 pada waktu kontak 120 menit, dan 0,775 pada waktu kontak 150 menit. Konsentrasi Fe pada waktu kontak 60 menit lebih tinggi dibandingkan konsentrasi Fe pada waktu kontak 30 menit. Hal ini disebabkan karena pada waktu kontak 30 menit, komposit telah jenuh sehingga penyerapannya tidak lagi optimal. Seiring penambahan waktu, terjadi pelepasan kembali logam Fe yang telah diserap, sehingga konsentrasi Fe pada waktu kontak 60 menit lebih tinggi. Berdasarkan hasil uji adsorpsi, komposit yang terdiri dari $25 \%$ claystone $25 \%$ zeolit dan $50 \%$ arang aktif tempurung kelapa telah berhasil menyerap logam Fe dalam AAT hingga 
memenuhi baku mutu hanya dalam waktu 30 menit. Hal ini berarti claystone dari material overburden batubara dapat dimanfaatkan sebagai material pembentuk komposit untuk menurunkan konsentrasi Fe dalam AAT. Selanjutnya efektivitas penyerapan komposit terhadap logam Fe dapat dilihat pada Gambar 5.

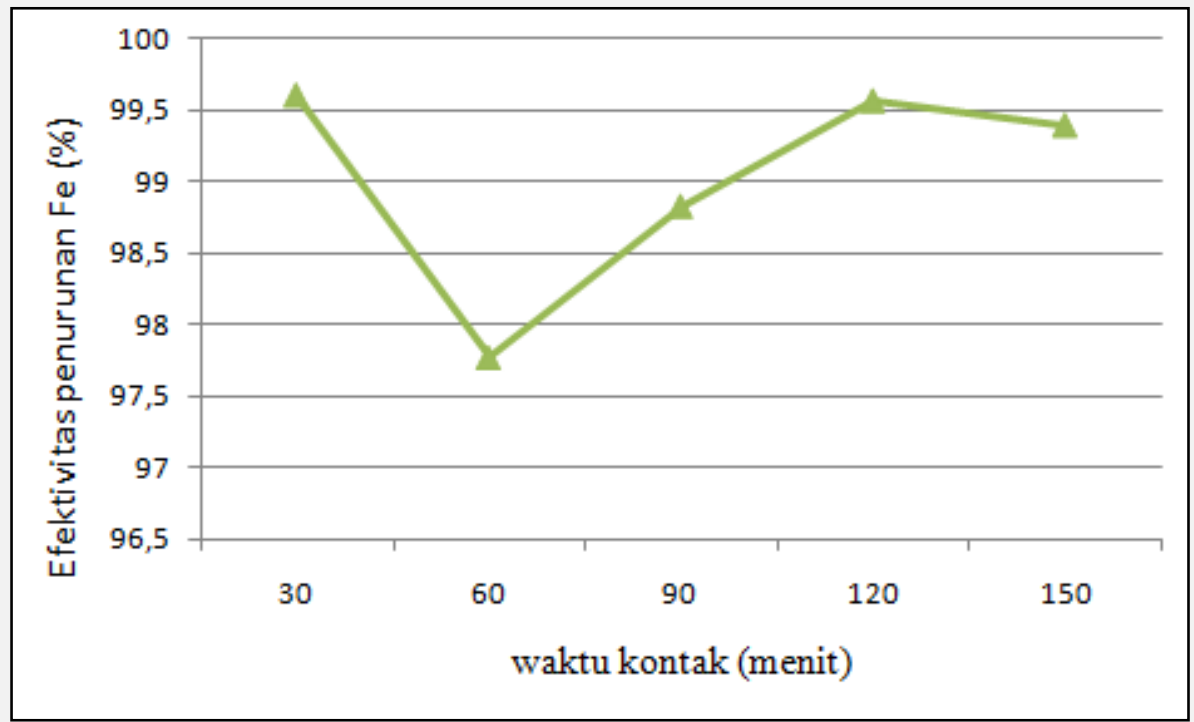

Gambar 5. Efektivitas adsorpsi komposit

Gambar 5 menunjukkan bahwa adsorpsi dengan waktu kontak 30 menit memberikan efektivitas penyerapan tertinggi yaitu 99,61\%. Efektivitas mulai menurun pada menit ke 60 menjadi $97,77 \%$, 98,83\% pada waktu kontak 90 menit, 99,57\% pada waktu kontak 120 menit dan 99,4\% pada waktu kontak 150 menit. Peningkatan efektivitas penyerapan komposit tidak signifikan seiring penambahan waktu kontak. Hal ini terjadi karena waktu kontak optimum adsorpsi adalah pada 30 menit, sehingga penyerapannya tidak lagi efektif dan begitu pula efektivitas adsorpsinya. Selanjutnya kapasitas adsorpsi dapat dilihat pada Gambar 6.

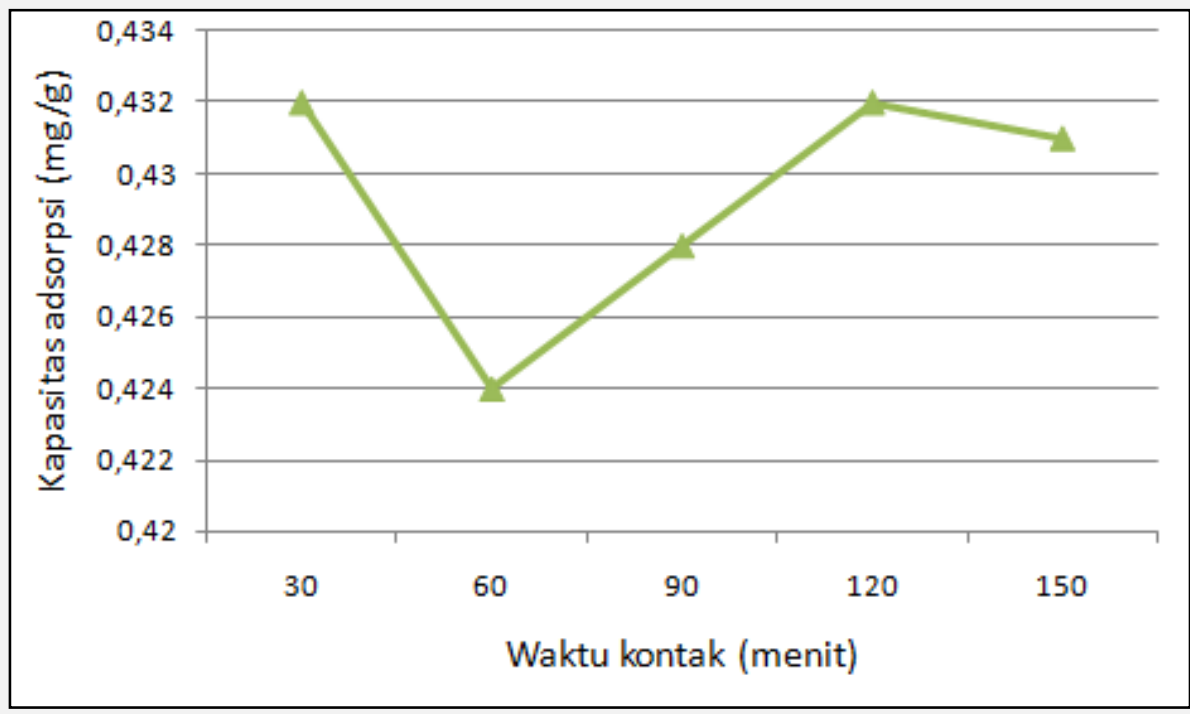

Gambar 6. Kapasitas adsorpsi komposit 
Berdasarkan Gambar 6, kapasitas adsorpsi oleh komposit pada menit ke 30 sebesar $0,432 \mathrm{mg} / \mathrm{g}$, dimana artinya tiap 1 gram komposit mampu menyerap Fe sebanyak 0,432 mg. Kapasitas adsorpsi mengalami penurunan pada menit ke 60 menjadi 0,424 mg/g, kemudian peningkatan kapasitas adsorpsi tidak lagi signifikan seiring penambahan waktu kontak karena masih di angka 0,4 mg/g hingga menit ke 150. Hal ini sejalan dengan hasil penentuan waktu kontak optimum adsorpsi, dimana komposit telah mengalami kejenuhan pada menit ke 30 sehingga berpengaruh terhadap kapasitas adsorpsinya. Kapasitas adsorpsi terbaik komposit terjadi pada waktu kontak 30 menit.

\section{SIMPULAN}

Claystone dari material overburden batubara, zeolit, dan arang aktif tempurung kelapa merupakan adsorben yang efektif untuk menurunkan konsentrasi Fe dalam AAT. Komposit berhasil menurunkan konsentrasi Fe hingga dibawah baku mutu. Waktu kontak untuk adsorpsi Fe adalah 30 menit dengan efektivitas 99,61\% dan kapasitas adsorpsi sebesar 0,432 $\mathrm{mg} / \mathrm{g}$.

\section{UCAPAN TERIMA KASIH}

Penulis mengucapkan terima kasih kepada Bapak Era dan Raymond yang telah memfasilitasi pengambilan sampel AAT dari Bontang, Kalimantan Timur.

\section{DAFTAR PUSTAKA}

Balintova, M., Holub, M., Stevulova, N., Cigasova, J., \& Tesarcikova, N. (2014). Sorption in Acidic Environment - Biosorbents in Comparison with Commercial Adsorbents. Chemical Engineering Transactions, 39, 625-630.[CrossRef]

Catri, C. R. (2016). The Effectiveness of Natural Zeolite as Metal Absorbent Copper (II) in Pool Water With Coloumn Adsorption Method. Jurnal Penelitian Saintek, 21(2), 87-95. [CrossRef]

Gobel, A.P. (2018). Efektifitas Pemanfaatan Fly Ash Batubara Sebagai Adsorben Dalam Menetralisir Air Asam Tambang Pada Settling Pond Penambangan Banko (PT. Bukit Asam Persero). Tbk. Jurnal Mineral Energi dan Lingkungan, 2(1), 1-11. [CrossRef]

Li, W., Peng, J., Zhang, L., Yang, K., Xia, H., Zhang, S., \& Guo, S. H. (2009). Preparation of activated carbon from coconut shell chars in pilot-scale microwave heating equipment at $60 \mathrm{~kW}$. Waste management, 29(2), 756-760. [CrossRef]

Martini, T., Astuti, F., \& Maharditya, W. (2020). Test The Effectiveness and Characterization of Quartz Sand/Coconut Shell Charcoal Composite as Adsorbent of Manganese Heavy Metal. In IOP Conference Series: Materials Science and Engineering (Vol. 858, No. 1, p. 012041). IOP Publishing. [CrossRef]

Mgbemena, C. O., Ibekwe, N. O., Sukumar, R., \& Menon, A. R. (2013). Characterization of kaolin intercalates of oleochemicals derived from rubber seed (Hevea brasiliensis) and tea seed (Camelia sinensis) oils. Journal of King Saud University-Science, 25(2), 149-155. [CrossRef]

Mukarrom, F., Karsidi, R., Gravitiani, E., Astuti, F., \& Maharditya, W. (2020). The assessment of claystone, quartz and coconut shell charcoal for adsorbing heavy metals ions in acid mine drainage. IOP Conference Series: Materials Science and Engineering (Vol. 858, No. 1, p. 012040). IOP Publishing. [CrossRef] 
Musso, T. B., Parolo, M. E., Pettinari, G., \& Francisca, F. M. (2014). Cu (II) and Zn (II) adsorption capacity of three different clay liner materials. Journal of environmental management, 146, 50-58. [CrossRef]

Nwosu, F. O., Ajala, O. J., Owoyemi, R. M., \& Raheem, B. G. (2018). Preparation and characterization of adsorbents derived from bentonite and kaolin clays. Applied Water Science, 8(7), 195. [CrossRef]

Tan, I. A. W., Abdullah, M. O., Lim, L. L. P., \& Yeo, T. H. C. (2017). Surface modification and characterization of coconut shell-based activated carbon subjected to acidic and alkaline treatments. Journal of Applied Science \& Process Engineering, 4(2), 186-194.

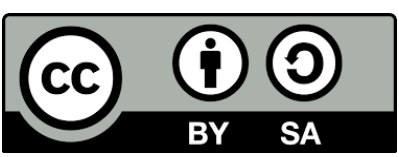

Copyright (c) 2021 by the authors. This work is licensed under a Creative Commons Attribution-ShareAlike 4.0 International License. 